\title{
Fake tense in Hausa counterfactuals: A novel argument for underspecified EXCL*
}

\author{
Malte Zimmermann \\ Universität Potsdam
}

\begin{abstract}
The paper presents a novel argument from Hausa (Chadic) for the analysis of counterfactual fake tense in terms of a lexically underspecified EXCLoperator (Iatridou 2000). Evidence comes from the facts (i.) that Hausa has no obligatory inflectional tense marking on the verb; and (ii.) that temporal anteriority and counterfactuality in Hausa are both expressed by a left-peripheral operator element with the segmental shape $d a a$, which is then tonally disambiguated to temporal dâa and counterfactual dàa, respectively. The analysis is cast in von Prince's (2019) modified branching-world model of counterfactuals.
\end{abstract}

Keywords: branching worlds, Chadic, counterfactuals, fake tense, Hausa, past tense, tenseless languages, understudied languages

\section{Introduction}

The phenomenon of fake tense, or fake past, is attested in various Western IndoEuropean languages, such as Greek or English. The main verb in the antecedent of counterfactual clauses appears to inflect for past tense, but without triggering a corresponding anteriority shift in the temporal domain, see (1):

(1) If Boris listened to the Scots (now), he would let them have a referendum.

Informally speaking, it appears that the obligatory finite -ed inflection on the verb can be used to express either a temporal shift away from the utterance time $t_{0}$, to yield an anteriority reading (past), or else a modal shift away from Lewis' (1986) actual world of evaluation $w_{0}$ (counterfactual fake past). The phenomenon has

\footnotetext{
* I would like to thank my native speaker consultants and colleagues Hasiyatu Abubakari and Abubakar Alkali for providing relevant data and discussion. Na gode! Thanks also to Frank Sode and the other participants of the Semantics Colloquium at Goethe University in Frankfurt/Main on 2 July 2020, as well as to the organizers and audience of SALT30, and in particular to Vesela Simeonova and Toshiyuki Ogihara, for insightful comments and suggestions. This work was carried out in the Project C02 "Limits of Variability in Interpretation", CRC1287, ProjectID 317633480 , funded by the German Research Foundation (DFG).
} 
received quite some attention in philosophy and formal semantics, following early work in Dudman 1983 and Iatridou 2000, with formal accounts largely falling into two camps: Past-as-past accounts take the inflectional PST marking on the counterfactual verb at face value and have it denote temporal anteriority, as in all other instances. Past-as-modal accounts hold, first, that the finite PST inflection comes with a modal interpretation in counterfactuals, and, second, that the identity of anteriority and counterfactual marking reflects a lexical underspecification in the meaning of PST inflection (Iatridou 2000, Schulz 2014, von Prince 2019, i.a.). In Iatridou 2000, the PST inflection denotes an underspecified exclusion operator EXCL, which leads to temporal or modal shift depending on context.

This contribution presents a novel argument from Hausa (Chadic, Afro-Asiatic) for the analysis of counterfactual fake tense in terms of a lexically underspecified EXCL operator à la Iatridou (2000) and von Prince (2019). Hausa differs from English or Greek in that it has no tense inflection on the verb whatsoever, which makes it a grammatically tenseless language (Mucha 2013). As a result, analyses that build on the semantic vacuity of inflectional (pro)forms, such as Schulz's (2014), will not apply. Still, even grammatically tenseless Hausa exhibits fake past, namely in the form of a left-peripheral operator that has the same segmental shape daa in both its temporal and in its modal shifting use. This tonally underspecified segment daa will be analyzed as an overt instantiation of the lexically underspecified EXCL-operator. Tonal specification then resolves the underspecified meaning to temporal dâa and counterfactual dàa construals, respectively. The analysis is cast in a branching-world model with language-specific constraints on the lexical meaning of - what appear to be - past-operators; see von Prince 2019.

\section{Fake past in tense-inflecting languages}

The term fake past refers to the fact that natural languages can express counterfactuality by inflectional past marking on the verb. The following minimal pair from Iatridou (2000) illustrates for Modern Greek. Whereas present tense (or rather: non-past) inflection on the verbs in the antecedent and consequent marks the conditional clause in (2a) as an indicative metaphysical conditional over situations in the actual world, the two verbs in the counterfactual conditional in (2b) carry a PST inflection.
a. An pari
afto to siropi $\quad \theta \mathrm{a} \quad \gamma_{1}$ ini
kala.
if take.NPST.PFV this syrup FUT become.NPST.PFV well 'If he takes this syrup, he will get better.'
b. An eperne afto to siropi $\theta \mathrm{a}$ yinotan kala. if take.PST.IPFV this syrup FUT become.PST.IPFV well 'If he took this syrup, he would get better.'


Fake Tense in Hausa Counterfactuals

The counterfactuals (CFs) in (3a-c) illustrate the same for English. In the three sentences, the antecedent verb carries PST morphology without a corresponding shift in the temporal domain: The CFs in (3a) and (3b) come with a present tense construal, as indicated by the temporal adverb now. The past CF in (3c) exhibits only a simple past shift instead of the double shift typically observed with periphrastic constructions consisting of past and perfect morphology.

(3) a. If Cem took this syrup (now), he would get better. FLV

b. If Cem was here (now), he would know the answer. PresCF

c. If Cem had taken this syrup (then), he would be better. PastCF

The future-oriented CF in (3a) is also labelled a future less vivid (FLV) conditional. It has the same assertion as a run-of-the mill hypothetical conditional, but an additional implicature that "the actual world is more likely to become a $\neg p$-world than a p-world" (Iatridou 2000: 234). Iatridou convincingly argues that FLV conditional clauses are present counterfactuals, too. The difference in interpretation follows from differences in verbal Aktionsart: CFs with telic VP-predicates, such as (3a), are interpreted as FLVs, whereas CFs with atelic VP-predicates denoting states or activities constitute present CFs. To see this, consider the atelic variant of (3a) in (4), in which the omission of the definite article induces an imperfective interpretation and the conditional is interpreted as a present $\mathrm{CF}$.

(5) If Cem took syrup, he would not cough.

PresCF

Iatridou (2000: 245) concludes that “ [...], FLVs, PresCFs, and PastCFs all contain a fake past. What is this fake past? There are, in principle, several ways to deal with a morpheme when it does not appear to be receiving its expected interpretation."

Before turning to the different ways of analyzing fake past, let us observe that the phenomenon also shows up in complement clauses of the counterfactual attitude verb wish, thereby marking the content of the wish as counterfactual:

(6) a. I wish I had a car (now/*yesterday).

b. I wish I had had a car (*now/ yesterday).

Iatridou (2000: 244) speculates that (6ab) may contain hidden CF conditionals, such that 'A wishes that B' would mean that 'A thinks that if B, she would be happy (that B).' This makes $\mathrm{CF}$ wishes another licensing environment for fake past.

\section{Previous analyses of fake past: Past-as-past vs. past-as-modal}

Existing formal accounts of fake past fall into two major classes. Next to backshifting approaches, which treat the PST inflection as denoting temporal anteriority across the board (past-as-past accounts, PAP), there are past-as-modal 
accounts (PAM), which treat PST inflection on the verb as expressing temporal remoteness (anteriority) or modal remoteness (CF conditionals), respectively.

\subsection{Past-as-past accounts: Temporal backshift in CFs}

PAP-accounts originate in Dudman 1983, 1984 and are also found in Ippolito 2003, Arregui 2009, Grønn \& von Stechow 2009, and Romero 2014, i.a. According to Dudman $(1983,1984)$, counterfactuals with so-called fake tense involve a genuine backshift in time, with a normal future indicative (metaphysical) conditional interpreted under a temporal past operator, which takes wide scope (7). In Ippolito's (2003: 60) terms, the metaphysical modal operator now quantifies over possible futures of the actual world relative to a certain contextually salient past time.

\section{(7) PAST [ MODAL metaphy [if FUT p] [then FUT g]]}

PST inflection thereby uniformly expresses temporal precedence in counterfactuals and other indicative clauses alike, but the PST morphology may be interpreted outside the CF if-clause. The resulting mismatch between surface position and interpretation site is responsible for the fake tense-effect.

Romero (2014) offers a compositional PAP-analysis that treats tense inflection as denoting a temporally constrained variable with a double-access interpretation. In the case of CFs, the tense variable introduced by the CF past morphology is ultimately bound by a wide-scoping covert PAST-operator $\exists_{1}$ pro1 through the binding chain in (8). Details aside, the fake tense effect arises because the bound tense variable pro6 induces no temporal shift: one of its specifications is locally $\lambda 5$ bound, whereas the second is interpreted relative to the utterance time proo.

(8) $\lambda 0\left[\exists_{1}\left[\right.\right.$ proo $_{1}{ }^{[\mathrm{PAST} T \mathrm{PrO}]}[\lambda 2 \mathrm{MODMETAPHY}$ pro 2

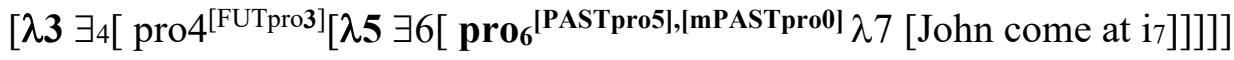

$$
\begin{aligned}
& [\lambda 3 \ldots \text { CONSEQUENT } \ldots]]]]
\end{aligned}
$$

On this account, PST morphology is locally interpreted in both antecedent and consequent clause of the counterfactual, at the cost of some formal complexity.

\subsection{Past-as-modal accounts: Remoteness}

PAM-accounts originate in Iatridou 2000, and are also found in Karawani \& Zeijlstra 2013, Karawani 2014, Schulz 2014, and von Prince 2019, i.a. Iatridou (2000) proposes that the verbal PST inflection denotes a lexically underspecified exclusion operator over the temporal or the modal domain. Depending on context, PST is interpreted either temporally, such that the topic time excludes the utterance time $t_{0},(9 a)$. Or it is interpreted modally, giving rise to a counterfactual reading, 
such that the topic worlds in the restriction of the universal modal quantifier exclude the actual world wo, (9b):

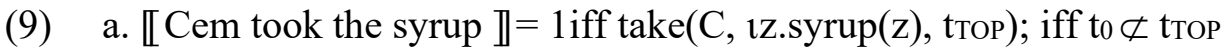

b. [If Cem took the syrup, he would get better $\rrbracket=1$ iff

$$
\forall \mathrm{w} \in \mathrm{W}_{\text {TOP }}\left[\text { take }(\mathrm{C}, \operatorname{zz} \cdot \operatorname{syrup}(\mathrm{z}), \mathrm{w}) \rightarrow \text { get_better(C, w)]; iff wo } \not \subset \mathrm{W}_{\text {TOP }}\right.
$$

On this account - which will provide the basis for the analysis of Hausa CFs to come - PST is a misnomer for the verbal inflection that is normally associated with temporal backshifting. Furthermore, although Iatridou (2000) is not concerned with compositionality per se, it appears possible to interpret the EXCL-operator denoted by PST in T or Mod. Finally, the double occurrence of PST in the antecedent and consequent of $\mathrm{CF}$ clauses is accounted for if exclusion is formulated as a constraint on possible value assignments to the local world variable $w$ in (9b).

Iatridou's proposal faces a number of problems, some of which have been discussed in subsequent literature. First, the exclusion semantics in (9a) does not rule out evaluation relative to a future topic time, contrary to fact (von Prince 2019):

(10) *Tomorrow, Cem took the syrup.

Iatridou (2000) tries to account for the ungrammaticality of (10) by restricting tense to range over past and present time intervals only, whereas future eventualities are expressed by a combination of modal shift and prospective aspect, as in Abusch 1985. But this does not answer the question of why contextually given topic times could not be located in the future. As a result, Iatridou (2000: 246, fn19) tentatively suggests to strengthen the exclusion semantics to a precedence semantics $<$, which may either be inapplicable or else vacuously satisfied in the modal CF case.

Second, Iatridou treats the respective contributions of PST inflection and the perfect participle in CFs on a par as operating in the tense domain (same as in most other formal treatments of fake past). However, it seems more appropriate to analyze the perfect as expressing aspectual information on the relation of ET and tTOP (Klein 1994), namely ET < tTOP, same as in non-counterfactual environments (Kratzer 1998, von Prince 2019). This is illustrated in (11) (Iatridou 2000: 252).

(11) If Rembrandt had already married five times by the time he was thirtyтов, we would have found traces of that in his self-portraits.

PST: modal exclusion; participle: ETMARRYING $<\mathrm{t}_{\mathrm{TOP}}\left(\ldots<\mathrm{t}_{0}\right)$

Third, the proposal does not account for past CFs with future orientation (Iatridou 2000: 252), i.e., Ogihara's (2000) mismatched past subjunctive clauses, as in (12); see also Ippolito 2003, 2013, Arregui 2007, and von Prince 2019.

(12) If Hasiya had arrived tomorrow, she would have missed the concert. 
Because of this, I will adopt the modified EXCL-analysis in von Prince (2019), in which the meaning of EXCL may be subject to further cross-linguistic variation.

Schulz (2014) offers an explicit compositional PAM-analysis that derives the semantic flexibility of the PST inflection from a structural ambiguity. Similar to Romero 2014, the PST inflectional morphology on counterfactual verbs is treated as a semantically vacuous form that is dependent on higher operators for semantic valuation. In Schulz 2014, the PST inflection comes with an uninterpretable feature [upast] which must be bound by a covert semantic operator and valued under feature transmission (von Stechow 2010). In particular, [upast] can be valued by a covert temporal PAST operator in T, (13a), or by the modal conditional quantifier $\square R$, resulting in the CF (13b). The interpretable feature [ipast] in (13ab) receives a unified treatment in terms of precedence, $(13 \mathrm{c})$, as already hinted at in Iatridou 2000: "The modal past, i.e. the modal variant of the past tense operator, [...] expresses anteriority, but now in the epistemic domain" (Schulz 2014: 132).

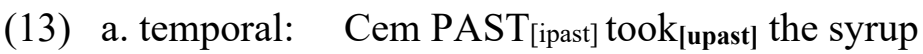

b. modal CF: [[ $\square \mathrm{R}_{\text {[ipast] }}\left[\right.$ if Cem took [upast] $_{\text {the syrup] }][\mathrm{q}]]}$

c. the feature [ipast] : $\lambda w \lambda \ldots . X<E^{*}$. OP(X)

Crucially, the modal [ipast] in counterfactuals is not interpreted locally in Mood, but outside the if-clause, resulting in an asymmetry of temporal and modal [ipast], which Schulz (ibid.: 138) defends on empirical grounds. The non-local interpretation of modal [ipast] as well as the bound variable nature of PST inflection make Schulz's (2014) account conceptually similar to Romero's (2014) PAPaccount. It will be seen shortly that the Hausa fake past data constitute evidence against both accounts, as these rely crucially on the presence of morphologically bound and semantically (near) vacuous proforms.

\subsection{Hypothetical past vs present $\mathrm{CF}$ conditionals}

All formal analyses capture the ambiguity of PST inflection in English conditional clauses between hypothetical past and present CF interpretations (Iatridou 2000). The ambiguity is typically resolved by temporal adverbials or contextual information and is not attested in tenseless languages with fake past, such as Hausa.

(14) a. If Cem took the syrup (then), he will be better now. HypoPast b. If Cem took the syrup (now), he would be better soon. PresCF

\section{A novel pattern: Fake past in grammatically tenseless Hausa}

This section presents the central empirical observations on fake past in grammatically tenseless languages, such as Hausa. $§ 4.1$ shows that Hausa is 
grammatically tenseless in the sense that there is no obligatory inflectional tense morphology on the verb, following Mucha 2013, 2015. $\$ 4.2$ then shows that Hausa has an optional adverbial past tense marker dâa 'formerly', 'back then' in the left clausal periphery. Finally, the data presented in $\S 4.3$ show that the segmental skeleton daa is involved in marking both temporal past and counterfactuality. Hausa thereby exhibits fake past in the absence of inflectional tense morphology; see also Bohnemeyer (2018) for similar observations on tenseless Yucatec Maya.

Hausa is a Western Chadic language from the Afroasiatic phylum. It is mainly spoken in Northern Nigeria and Niger, with smaller sub-communities across all neighboring countries. The total number of speakers is estimated at more than 70 mio (www.ethnologue.com), which makes Hausa one of the most important indigenous languages of inland Sub-Saharan Africa. Hausa exhibits rigid SVO order and no case marking, but it allows for syntactic focus fronting (Newman 2000). Topical material is typically realized in sentence-initial position. Hausa has obligatory aspectual markers immediately preceding the verb. ${ }^{1}$ Finally, it is a tone language with $\mathrm{H}, \mathrm{L}\left({ }^{\prime}\right)$, and falling $\mathrm{HL}\left({ }^{\wedge}\right)$ tones, which also mark grammatical distinctions concerning sentence type and aspect.

The data for this study are mostly taken from the existing literature on the formal properties of tense (non-) marking and counterfactuals (Newman 2000, Mucha 2013, 2015). Additional semantic judgments on individual counterfactual and tensed clauses were elicited via email from two native speaker linguists, one of them hailing from Sokoto (Nigeria) and one from the diaspora community in Accra (Ghana). Validation of these data with additional speakers is planned.

\subsection{Hausa is grammatically tenseless}

Mucha $(2013,2015)$ shows that Hausa is grammatically tenseless. There is no obligatory morphological coding of temporal information on $\mathrm{V}$, nor in the extended verbal domain in $\mathrm{T}$. As a result, the tenseless clauses in (15ab) can make reference to a past, present, or future topic time, depending on context (Mucha 2013: 381).

$$
\begin{array}{ll}
\text { a. Ta-nàa wàasaa } & \text { b. Sun gyaarà mootà-sà } \\
\text { 3SG.F.-IPFV play } & \text { 3PL.PFV repair car-3SG.M.POSS } \\
\text { 'She is/was/will be playing.' } & \text { 'They (have/will have) repaired his car.' }
\end{array}
$$

Mucha $(2013,2015)$ shows that, in the absence of context, PFV and IPFV aspect trigger default interpretations as present and past tense, respectively, in line with the general pragmatic resolution strategies in Smith \& Erbaugh 2005. Future time reference is typically expressed by the future marker záa. Still, context can always

\footnotetext{
${ }^{1}$ I adopt Mucha's $(2013,2015)$ analysis of Hausa PFV and IPFV aspect as essentially temporal. Perfective (PFV) and imperfective (IPFV) aspect express relations between event time and topic time (Klein 1994), with PFV including event time within topic time, and IPFV vice versa.
} 
overwrite temporal reference in the absence of grammatical tense specifications. (16) from Mucha (2013: 387) shows that reference to a future topic time is contextually licensed in the absence of the future marker zaa.

(16) Context: What will Bashir be doing when I come home tomorrow afternoon?

Bashir ya-nàa wàasaa gòobe

Bashir 3SG.M-IPFV play tomorrow

'Bashir will be /*was playing tomorrow (...when you come home).'

\subsection{Optional tense marking in Hausa}

In spite of its grammatical tenselessness, Hausa allows for the optional marking of past tense. Explicit reference to a past topic time can be made with the sentenceinitial adverb dâa (Newman 2000: 35), which is realized with falling HL-tone and normally translated as 'back then' or 'formerly'; see (17). Dâa is plausibly analyzed as a frame-setting past restrictor of Kleinian (1994) topic times. Its topic status is further evidenced by its frequent co-occurrence with the topic marker maa, as shown in (18) (from Newman \& Newman 1979: 22):

(17) Dâa i-nàa ciyar dà ìyaalìi,...

PST 1SG-IPFV feeding $P$ family

'Formerly, I could provide for my family, ...' (lit. 'was feeding')

(18) Dâa maa naa san haká zâ-a yi.

PST TOP IPFV know so FUT-3SG happen

'I knew beforehand that this would happen.' (lit. 'that one would do so')

This observation is relevant since left-peripheral topical elements typically have semantic content, unlike the bound inflectional tense preforms in Schulz 2014 and Romero 2014. If the overt optional tense marker dâa were bound by a higher covert PAST operator, as in these accounts, there would actually be two elements in the left-periphery, one semantically active and covert and the other semantically inactive and overt, (19). But why assume an additional covert operator if dâa is already in the right structural position to do the job?

(19) * ØраSTi [тор dâapast,i [тр ... ]]

\subsection{Conditional clauses and fake tense in Hausa counterfactuals}

Indicative metaphysical conditionals in Hausa feature the obligatory COMP-head ìdan/in: (Newman 2000: 126).

(20) In yâaraa sun daawoo zâ-n baa sù kwabòo kwabòo. if children 3PL.PFV return FUT-1SG give 3PL penny penny 
Fake Tense in Hausa Counterfactuals

'If the children come back, I will give them a penny each.'

Interestingly, the telic perfective aspect of (20) does not trigger a default hypothetical past interpretation, unlike in matrix clauses, but it gives rise to a futurenear-vivid interpretation (Iatridou 2000). Kaufmann (2005) has argued that indicative metaphysical conditionals have a future orientation even in the absence of overt will or zaa. It is therefore possible that this future orientation is built into the meaning of the conditional complementizer in/idán in Hausa. As a result, PFV aspect in (20) will locate the event time inside a future evaluation time. Finally, hypothetical past conditionals, cf. English (14a), are expressed with the temporal past marker dâa, as shown in the elicited clause in (21):

(21) In dâa yâaraa sun daawoo zâ-n baa sù kwabòo kwabòo.

if PST children 3PL.PFV return FUT-1 give 3PL penny penny

'If the kids have already come back, I will give them a penny each.'

Turning to Hausa counterfactuals, these must be marked by L-toned dàa in the left periphery of antecedent and consequent. Dàa is optionally accompanied by the complementizer in. Out of context, present and past CF construals are distinguished by aspect, same as in declarative main clauses. Imperfective (22a) receives a default present interpretation, whereas perfective (22b) is interpreted as past. ${ }^{2}(22 \mathrm{c})$ shows that CF marking is also compatible with future marking, resulting in a FLVinterpretation (Iatridou 2000); all examples are taken from Newman (2000: 127).

$\begin{array}{llllll}\text { a. (In) dàa su-nàa fad'àa, dàa mu-nàa jîn } & \text { iihùu. } \\ \text { if } & \text { CF } & \text { 3PL.IPFV fighting } & \text { CF } & 1 \text { PL-IPFV } & \text { hearing } \\ \text { shouts }\end{array}$ 'If they were fighting, we would be hearing shouts.' $\quad$ PresCF

b. (In) dàa kun ci wannàn ganyee, dàa kun mutù. if $\quad \mathrm{CF}$ 2PL.PFV eat this leaf CF 2PL.PFV die 'If you had eaten these leaves you would have died.' PastCF

c. Dàa zaa sù zàab'ee shì dàa zâ-i cùucee sùu. CF FUT 3PL elect 3SG CF FUT-3SG.M cheat 3PL 'If they were to elect/elected him, he would cheat them.' $\quad$ FLV

Setting the semantic contribution of (modalized) aspect aside, we thus find that the temporal orientation of Hausa CFs is largely determined by aspect, same as in English. Unlike in English, though, Hausa CFs with telic PFV-predications do not get a default interpretation as FLV, but as past CF, (22b). Also, while FLVinterpretations typically require the future marker záa or potential aspect in the antecedent, there are exceptions with perfective aspect (Newman: 127f.):

\footnotetext{
${ }^{2}$ Vesela Simeonova points out that (22a) should also allow for a past imperfective interpretation when the local reference time $\mathrm{t}_{\mathrm{TOP}}$ is contextually shifted to the past: 'If they had been fighting (at the topic time), we would have been hearing shouts'. I will leave this matter for future investigation.
} 
(23) Dàa kaa sàamifâm dubuu hàmsin dàa zaa-kà sàyi Marsandî? CF 2SG.M.PFV get pound thousand 50 CF FUT-2SG.M buy Mercedes 'If you were to get $£ 50.000$ (which you are not), would you buy a Mercedes?'

In other cases, the combination of CF marking plus perfective aspect also allows for a past CF with a future orientation; see the elicited (24) and English (12) above.

(24) CONTEXT: Abla taa daawoo jiyà, ... / 'Abla returned yesterday...'

In dàa gòobe ta daawoo ne, dàa taa rasà konseti nnàn if CF tomorrow 3SG.F.PFV return FOC CF 3SG.F.PFV miss concert DEM 'Had she (only) returned tomorrow, she would have missed the concert.'

Notice incidentally that (24) features syntactic focus fronting of the temporal adjunct gòobe, suggesting that the notion of contrast does indeed play a crucial role in the interpretation of such future-oriented past CFs; see Ogihara 2000, Ippolito 2003. Finally, counterfactual wishing is also expressed with dàa (Newman 2000), namely in the form of a truncated conditional optative (Biezma 2011); see (25) from Newman 2000. The use of the truncated conditional follows from the fact that the embedding attitude verb sô 'wish' selects for infinitival clauses only. ${ }^{3}$

$$
\begin{array}{lllll}
\text { Dàa maa i-nàa } & \text { dá mootàa } & \text { nee } & \text { (Newman 2000: 128) } \\
\text { CF TOP 1SG-IPFV } & P \text { car } & \text { FOC/EXCL } & \\
\text { 'If only I had a car.' } & & &
\end{array}
$$

The optative interpretation of (25) is supported by the clause final focus particle nee, which Hartmann \& Zimmermann 2007 analyze as an exclusive operator; see also Grosz 2013 on the role of exclusive particles in marking optatives and in CFs.

\subsection{Summary and problems for earlier accounts}

The facts presented show that Hausa differs from tensed languages in that there is no obligatory inflectional tense morphology on the verb. At the same time, Hausa is similar to English in exhibiting a formal parallel between the optional marking of past tense and the marking of CF-conditionals: In Hausa, the operator elements used in past- and CF marking share the same segmental skeleton. The fact that these elements occur in a left peripheral topic position suggests that it is these elements that contribute the relevant semantic content. This is consistent with Iatridou's (2000) PAM-analysis of PST in terms of semantically underspecified EXCL.

\footnotetext{
${ }^{3}$ Another syntactic environment licensing dàa is the syntactic complement of the (deontic) weak necessity modal yaa kàmaatà 'it would be better', 'should'. Such weak necessity modals feature subjunctive/CF or past morphology in many languages (von Fintel \& Iatridou 2008), and they have recently been analyzed in Yalcin (2016) as involving a counterfactual normality claim. Hence, the occurrence of dàa is not unexpected. Thanks to Frank Sode for raising this empirical issue!
} 
Fake Tense in Hausa Counterfactuals

In contrast, the Hausa facts pose a problem for the other analyses discussed in $\S 2$. The fact that dàa occurs in the antecedent and consequent clause of CFconditionals constitutes evidence against locating the entire conditional in the scope of a single covert past operator; see Dudman 1983, 1984. Romero's (2014) compositional PAP-version is based on the presence of inflectional morphology on the verb, which is semantically bound by a higher covert past operator. There are no such inflectional elements in Hausa, though. Instead, the temporal marker dâa and the CF-marker dàa appear to be left-peripheral operator elements with semantic content. A similar problem applies to the compositional PAM-account of Schulz 2014, which relies on the presence of semantically vacuous inflectional preforms in need of valuation by a higher covert operator. Again, temporal dâa is not an inflectional element, but grammatically optional, and it is the only interpretable temporal expression in indicative main clauses. Moreover, its presence or absence determines the semantic difference between hypothetical past conditionals, on the one hand, and future-oriented present counterfactual conditionals, on the other. This shows, once more, that dâa is semantically active. All in all, then, the Hausa facts seem best amenable to an EXCL-operator analysis à la Iatridou (2000), where EXCL is overtly expressed by dâa and dàa, respectively.

\section{A branching-world analysis of fake past $=E X C L$}

The formal parallels between optional past marking and CF marking in Hausa are neatly accounted for in von Prince's (2019) revised version of Iatridou's (2000) classic PAM-account in terms of EXCL operators. The analysis of dâa/dàa involves the following ingredients:

- It is cast in the branching-world paradigm of Prior 1957, 1967, and Thomason 1970, with evaluation indices consisting of world-time pairs. There is no separate treatment of times and worlds in semantic evaluation.

- Adopting von Prince's (2019) 3D-modality, it involves a tri-partite distinction into actual, possible, and counterfactual indices.

- The CF/PAST skeleton daa without tonal specification is analyzed as a semantic operator inducing a shift of the evaluation index away from the actual index and its successors, corresponding to von Prince's (2014) treatment of the English simple (inflectional) past (ESP).

- The exact domain of index shifting is resolved by overt tonal specification with $\mathrm{HL}$ and L tone, respectively, unlike in English.

- The analysis allows for cross-linguistic variation in the meaning of PAST and CF-operators (von Prince 2019), and thereby for cross-linguistic differences in the coding of past tense and CF, including the absence of fake past. 


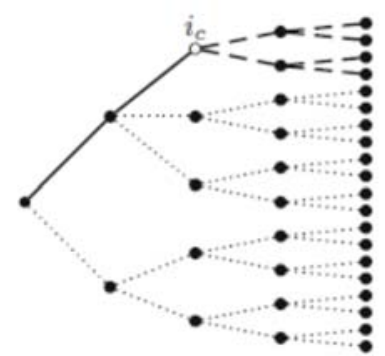

Figure 1 Branching Worlds (von Prince 2019: 591)

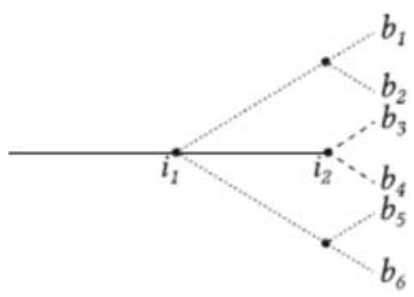

Figure 2 3D-modality

(von Prince 2019: 592)

\subsection{Introducing branching worlds}

In the branching-world models of Prior 1957, 1967, and Thomason 1970, time is taken as an absolute. Indices are time-world pairs, where simultaneous indices are vertically aligned in Fig.1. The actual index of utterance time and actual world $<\mathrm{t}_{\mathrm{c}}$, $\mathrm{w}_{\mathrm{c}}>$ is singled out as $i_{c}$. Branches are maximal linearly ordered subsets on the set of indices $I$, where linear ordering corresponds to temporal precedence. Different branches, marked as solid, or dotted or dashed horizontal lines in Figs. 1 and 2, constitute different alternative histories, i.e., different ways in which the world could develop over time. The solid line leading up to $i_{c}$ in Fig.1 constitutes the actual history consisting of actual past and the actual now index. The dashed lines single out actual future possibilities, i.e., the ways in which the actual world may develop after now, and the dotted lines indicate counterfactual possibilities, i.e., the ways in which the world might have developed otherwise. Unlike Thomason (1970), von Prince (2019: 591) also allows for quantification over worlds that are not identical up to $i_{c}$. The resulting three-way distinction into actual, possible future, and counterfactual indices, hence 3D-modality, is illustrated in Fig.2. The actual indices are $i_{2}$ and all predecessors of $i_{2}$, including $i_{1}$. The possible future indices are all successors of $i_{2}$, i.e., $b_{3}$ and $b_{4}$. And the counterfactual indices are neither predecessors nor successors of $i_{c}$, nor identical with it, i.e., $b_{1}, b_{2}, b_{5}, b_{6}$, and the unlabelled indices vertically aligned with $i_{c}$. Von Prince's 2019 modified branching worlds thereby allow for a distinction between actual $\left\{b_{3}, b_{4}\right\}$ and counterfactual future possibilities $\left\{b_{1}, b_{2}, b_{5}, b_{6}\right\}$. This will be relevant for the analysis of (mismatched) past CFs with future time reference; see Ogihara 2000, Ippolito 2003.

\subsection{The meaning of the English Simple Past and would}

Against the background of 3D-branching worlds, von Prince (2019: 593) proposes the following meaning for the English Simple Past (ESP) inflection: 
Fake Tense in Hausa Counterfactuals

$$
\llbracket \mathrm{ESP} \rrbracket=\lambda \mathrm{p}_{<\mathrm{i} i} . \lambda \mathrm{i}: \mathrm{i} \in \mathrm{TOP}, \mathrm{i} \in\left\{\left\{\mathrm{i}^{\prime} \mid \mathrm{i}^{\prime}<\mathrm{ic}\right\} \cup\left\{\underline{\mathrm{i}^{\prime} \mid} \mid \mathrm{t}(\mathrm{ic}) \leq \mathrm{t}\left(\mathrm{i}^{\prime}\right), \neg\left(\mathrm{ic}^{\mathrm{i}} \leq \mathrm{i}^{\prime}\right)\right\}\right\} \cdot \mathrm{p}(\mathrm{i})
$$

The simple past tense morphology of English thereby denotes a partial function over propositions $p$ (sets of indices) that restricts the set of accessible evaluation indices $i$ for $p$ by adding a disjunctive presupposition. The propositional modifier ESP will only pick out those propositions that are true (i.) for topical indices that are predecessors of $i_{\mathrm{c}}$ on the actual branch (= actual past), or else (ii.) for topical indices that are located at times simultaneous or after the time of the actual index ic, but not for possible successors of ic or the actual index ic (= counter-factual). In brief, ESP is a misnomer in that it does not restrict evaluation to past indices alone. Instead, it means anything but $i_{C}$ or possible futures, which makes it a bona fide underspecified EXCL-operator ranging over both past and CF-indices, and nothing else. Notice that set union results in a flattening of the two index sets into a new set, which may be appropriate for English and the Oceanic language Dakaaka, in which past and irrealis sentences are also marked by the same morpheme (von Prince 2017). Finally, the past auxiliary would in the consequent clause of English CFs picks out all propositions that are true for indices that are located at times simultaneous to or after the time of the actual index $i_{c}$, but not for possible successors of $i_{c}$ or $i_{c}$ itself. The presupposition of would only consists of the second disjunct in (26), which singles out the set of counter-factual indices in present or future, corresponding to the Latin or German mood of conjunctivus irrealis:

$$
\llbracket \text { would } \rrbracket=\lambda \mathrm{p}_{<\mathrm{i}>} . \lambda \mathrm{i}: \mathrm{i} \in \mathrm{TOP}_{\mathrm{I}}, \mathrm{i} \in\left\{\underline{\left\{\mathrm{i}^{\prime} \mid \mathrm{t}(\mathrm{ic}) \leq \mathrm{t}\left(\mathrm{i}^{\prime}\right), \neg\left(\mathrm{ic} \leq \mathrm{i}^{\prime}\right)\right\}}\right\} \text {. p(i) }
$$

Crucially, counterfactual indices in the past of ic are neither in the denotation space of ESP nor of would. They require additional marking by perfect aspect in a past CF clause, such that perfect aspect introduces a new index $i$ ' preceding the topical index $i$ (Kratzer 1998), which is constrained by ESP, (28b):

$$
\begin{aligned}
& \text { a. } \left.\llbracket \text { PERF } \rrbracket=\lambda p<i>. \lambda i . \exists i{ }^{\prime}\left[t^{\prime}{ }^{\prime}\right)<t(i)\right] \wedge p\left(i^{\prime}\right)
\end{aligned}
$$

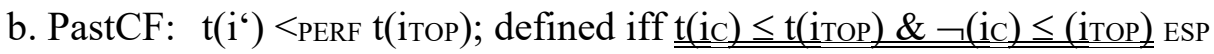

\subsection{Extending the analysis to Hausa}

The Hausa markers for past tense (dâa) and CF (dàa) share the same segmental skeleton, but they differ in tone. The core proposal is that the meaning of the skeletal core daa equals that of English ESP in (26). Tonal marking then results in a lexical specification in the semantic space of daa to temporal past or modal CF readings, respectively. Finally, grammatical and lexical aspect add information on temporal sequencing and in particular on the temporal positioning of the event index relative to the topic index, which is directly constrained by dâa and dàa .

(29ab) show the meaning of the surface forms dâa and dàa: the past meaning (29a) corresponds to the first disjunct in (26), and the CF meaning (29b) to the 
second. We will return to the question of whether (29ab) can be derived from the flattened disjunctive ESP-meaning in (26), or whether a revision is called for.

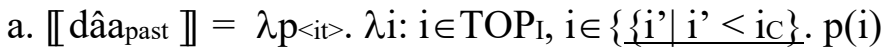

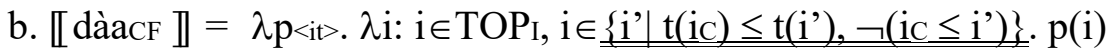

With (29ab), the meaning of the basic examples in (17) and (22ab) is derived as follows. The topic index $i$ of the declarative in (17), repeated, is shifted into the actual past with the optional past tense marker dâa. Imperfective aspect then locates the topic time $t(i)$ as fully contained inside the event time $t(i$ ') of the speaker providing for the family:

(17) Dâa i-nàa ciyar dà ìyaalìi, ... (Newman 2000: 35)

PST 1SG-IPFV feeding $P$ family

(30) $\llbracket(17) \rrbracket=1$ iff $\exists i^{\prime}\left[I\right.$ feed_family(i') $\left.\wedge t(i) \subset t\left(i^{\prime}\right)\right]$, iff $i \in T O P I, ~ i \in\left\{i^{\prime} \mid i^{\prime}<i^{c}\right\}$

$=1$ iff there is a topical index $i$ in the actual past (= preceding $\left.i_{c}\right)$ such that the speaker was providing for her family at $i$.

The interpretations of the present and past CFs in (22ab) are derived as follows. Since the CF-marker dàa is found both in the antecedent and the consequent clause, and in the absence of a modal would-auxiliary, I locate the quantificational force of CF in the (optional) complementizer in. Following von Prince (2019: 596, 26), the meaning of in is given in (31):

(31) $\llbracket$ in $\rrbracket=\lambda p_{<i t>.} \lambda q_{<i t>} . B_{p} \subseteq B_{q}$; where $B_{\phi}=\left\{b \mid b \in R_{B}, \exists i \in b . \phi(i)\right\}=$ the set of those contextually relevant branches that contain an index for which $\phi$ is true.

The modal universal quantifier in takes two propositions and states that the set of branches that contain an index verifying the antecedent $p$ is a subset of the set of branches containing an index that verifies the consequent $q$. As a result, any index verifying $p$ will be on a branch with an index verifying $q$. With (29b) and (31), the meaning of the present CF in (22a) is derived as in (32):

(22) a. (In) dàa su-nàa fad'àa, dàa mu-nàa jîn iihùu.

If CF 3PL-IPFV fighting CF 1CF-IPFV hearing shouts

(32) a. $\mathrm{p}=\lambda \mathrm{i}: \mathrm{i} \in \mathrm{TOP}, \mathrm{i} \in\left\{\mathrm{i}^{\prime} \mid \mathrm{t}\left(\mathrm{i}_{\mathrm{c}}\right) \leq \mathrm{t}\left(\mathrm{i}^{\prime}\right), \neg\left(\mathrm{i}_{\mathrm{c}} \leq \mathrm{i}^{\prime}\right)\right\}$. $\exists \mathrm{i}^{\prime}$ [they fight at $\mathrm{i}^{\prime} \wedge \mathrm{t}\left(\mathrm{i} \subset \mathrm{t}\left(\mathrm{i}^{\prime}\right)\right]$

b. $q=\lambda i: i \in T^{\prime} P_{I}, i \in\left\{i^{\prime} \mid t\left(i_{c}\right) \leq t\left(i^{\prime}\right), \neg\left(i_{c} \leq i^{\prime}\right)\right\}$.

$\exists i^{\prime}\left[\right.$ we hear shouts at $\left.i^{\prime} \wedge t(i) \subset t\left(i^{\prime}\right)\right]$

c. $\llbracket(22 a) \rrbracket=1$ iff $B_{p} \subseteq B_{q}$; defined iff $i \in T O P I, i \in\left\{i^{\prime} \mid t\left(i_{c}\right) \leq t\left(i^{\prime}\right), \neg\left(i_{c} \leq i^{\prime}\right)\right\}$

(22a) is thereby true iff the set of branches containing a CF-index verifying $\lambda i$. $\exists i$ ' they fight at $i^{\prime}$, and $t(i) \subset t\left(i^{\prime}\right)$ is a subset of the set of branches containing a CFindex verifying $\lambda i$. $\exists i$ ' we hear shouts at $i^{\prime}$, and $t(i) \subset t(i ')$. That is, any branch containing a CF-index at which they are fighting (now) is a branch containing a 
Fake Tense in Hausa Counterfactuals

CF-index at which we would be hearing shouts (now). The meaning derivation for the past CF in (22b) is entirely parallel, as shown in (33).

$$
\begin{array}{lllllll}
\text { b. (in) dàa } & \text { kun ci wannàn ganyee, dàa kun mutù. } \\
\text { if } & \text { CF } & \text { 2PL.PFV eat this leaf } & \text { CF } & \text { 2PL.PFV die }
\end{array}
$$

$$
\begin{aligned}
& \text { a. } p=\lambda \mathrm{i}: \mathrm{i} \in \mathrm{TOP}, \mathrm{i} \in\left\{\mathrm{i}^{\prime} \mid \mathrm{t}(\mathrm{ic}) \leq \mathrm{t}\left(\mathrm{i}^{\prime}\right), \neg\left(\mathrm{ic} \leq \mathrm{i}^{\prime}\right)\right\} \text {. } \\
& \exists i^{\prime}\left[\text { you eat leaves at i' } \wedge t\left(i^{\prime}\right)<t(i)\right] \\
& \text { b. } q=\lambda i: i \in T^{\prime} P_{I}, i \in\left\{i^{\prime} \mid t(i c) \leq t\left(i^{\prime}\right), \neg\left(i c \leq i^{\prime}\right)\right\} . \\
& \left.\exists i^{\prime} \text { [you die at i' and } t\left(i^{\prime}\right)<t(i)\right] \\
& \text { c. } \llbracket(22 b) \rrbracket=1 \text { iff } B_{p} \subseteq B_{q} \text { defined iff } i \in T_{O P}, i \in\left\{i^{\prime} \mid t\left(i_{c}\right) \leq t\left(i^{\prime}\right), \neg\left(i_{c} \leq i^{\prime}\right)\right\}
\end{aligned}
$$

(22b) is thereby true iff the set of branches containing a CF-index verifying $\lambda i$. $\exists i$ ' you eat these leaves at $i^{\prime}$, and $t\left(i^{\prime}\right)<t(i)$ is a subset of the set of branches containing a CF-index verifying $\lambda i$. $\exists i^{\prime}$ you die at $i^{\prime}$ and $t\left(i^{\prime}\right)<t(i)$. That is, any branch containing a CF-index at which the addressee ate these leaves before now is a branch containing a CF-index at which the addressee died before now. For simplicity, I gloss over differences between English-style PERF aspect in terms of temporal precedence and Hausa PFV aspect in terms of temporal inclusion, and simply treat Hausa PFV ( $\left.\left(\mathrm{i}^{\prime}\right) \subset \mathrm{t}(\mathrm{i})\right)$ as inducing a temporal backshift in CFs: $\mathrm{t}\left(\mathrm{i}^{\prime}\right)$ $<\mathrm{t}$ (i). It remains to be seen how this would square with Mucha's $(2013,2015)$ pragmatic account of default temporal backshifts with PFV à la Smith \& Erbaugh 2005 , which crucially relies on the instantaneousness of utterance time. Are counterfactual topical indices also instantaneous, then? Alternatively, the temporal backshift may be triggered by a covert PERF operator, which can also be overt. Interestingly, one consultant added the aspectual element tun(i) 'since, long ago' (Newman: 35) in elicited translation, see (34). The slot between aspect and V is reserved for functional elements. (34) is in need of additional validation, though!

(34) In dàa Binta ta (tun) sha magani nnan daazu, dàa ta (tun) gyi sawki. if $\mathrm{CF}$ B. 3SG.F.PFV ASP drink medicine this then CF 3SG.PFV ASP recover 'If Binta had taken the medicine back then, she would have recovered.'

Finally, the analysis also accounts for past CFs with future reference (Ogihara 2000). (24) is true iff the set of branches containing a CF-index verifying $\lambda i$. $\exists i$ ' Abla returns at $i$ ' and $i$ ' $\subset i$ and $i$ is tomorrow is a subset of the set of branches with a CF-index verifying $\lambda i$. $\exists i$ ' Abla misses the concert in i' and $i$ ' $\subset i$ and $i$ is tomorrow. That is, any branch containing a CF-index at which Abla returns the day after is a branch containing a CF-index at which she misses the concert then.

(24) In dàa gòobe ta daawoo ne, dàa taa rasà konseti nnàn if $\mathrm{CF}$ tomorrow 3SG.F.PFV return FOC CF 3SG.F.PFV miss concert DEM 'Had she (only) returned tomorrow, she would have missed the concert.' 


$$
\begin{aligned}
& \text { a. } p=\lambda \mathrm{i}: \mathrm{i} \in \mathrm{TOP}, \mathrm{i} \in\left\{\mathrm{i}^{\prime} \mid \mathrm{t}(\mathrm{ic}) \leq \mathrm{t}\left(\mathrm{i}^{\prime}\right), \neg\left(\mathrm{ic} \leq \mathrm{i}^{\prime}\right)\right\} \text {. } \\
& \exists i^{\prime}[\text { Abla returns at i' \& t(i') } \subset \mathrm{t}(\mathrm{i}) \& \mathrm{t}(\mathrm{i}) \in \text { tomorrow ] } \\
& \text { b. } q=\lambda i: i \in T_{O P I}, i \in\left\{i^{\prime} \mid t(i \mathrm{c}) \leq t\left(i^{\prime}\right), \neg\left(i_{C} \leq i^{\prime}\right)\right\} C F \text {. } \\
& \exists i^{\prime}[\text { Abla misses concert at i' \& t(i') } \subset \mathrm{t}(\mathrm{i}) \& \mathrm{t}(\mathrm{i}) \in \text { tomorrow ] } \\
& \text { c. } \llbracket(24) \rrbracket=1 \text { iff } \mathrm{B}_{\mathrm{p}} \subseteq \mathrm{B}_{\mathrm{q}} \text { defined iff } \mathrm{i} \in \mathrm{TOP}_{\mathrm{I}}, \mathrm{i} \in\left\{\underline{\left.\mathrm{i}^{\prime} \mid \mathrm{t}\left(\mathrm{i}_{\mathrm{c}}\right) \leq \mathrm{t}\left(\mathrm{i}^{\prime}\right), \neg\left(\mathrm{i}_{\mathrm{c}} \leq \mathrm{i}^{\prime}\right)\right\}}\right.
\end{aligned}
$$

\subsection{On tonal specification: a plea for structure in proposition disjunction}

We still need to answer the question of how to derive the meanings of the disambiguated surface forms dâa and dàa in (29ab) from the underspecified disjunctive meaning of the skeletal core daa in (26). In a first attempt, the specific meanings in (29ab) may be derived by intersecting the set-union of indices in (26) with the more specific presuppositions of HL and L tone, respectively; see, e.g., Ippolito 2003 on intersecting presuppositions. Technically, this might work if the intonational meaning of $\mathrm{HL}$ and $\mathrm{L}$ were conceptualized as a presuppositiontriggering modifier of type $<<\mathrm{it}$, it $>,<\mathrm{it}, \mathrm{it}>>$, as shown for HL tone in (36). In the course of applying (36) to $(26)(=\mathrm{P})$, the individual presuppositions on possible index values are intersected, resulting in temporaö backshift.

$$
\mathbb{I}^{\wedge} \rrbracket=\lambda \mathrm{P}<\mathrm{it,it>} . \lambda \mathrm{p}_{<\mathrm{it}>} . \lambda \mathrm{i}: \mathrm{i} \in \mathrm{TOP}, \mathrm{i} \in\left\{\underline{\left.\mathrm{i}^{\prime} \mid \mathrm{i}^{\prime}<\mathrm{ic}\right\}} . \mathrm{P}(\mathrm{p})(\mathrm{i})\right.
$$

However, this procedure requires postulating very specific meaning contributions for HL and L tone, which are not attested elsewhere in Hausa. Moreover, it would be at odds with other instances of tonal specification or disambiguation, which is a rather common feature of Hausa. For instance, the choice between HL and LH tonal pattern on the proximal demonstrative skeleton wannan in (37ab) determines whether the proximal center is the speaker or the addressee. With the spatial or temporal deictic adverb nan, tone disambiguates between proximal and distal meanings, (37cd) (Newman 2000: 36, 147).
a. wannàn 'this (by me)'
b. wànnan 'this (by you)'
c. nân 'here, now'
d. nan 'there near you, then'

At the clause level, tonal specification determines the clause-type of canonical sentences as declarative (falling intonation) or interrogative (final rise); see Newman \& Newman 1981, Leben et al. 1989. The widespread occurrence of tonal specification in Hausa, with different tone patterns and different semantic effects, constitutes a strong argument against the specific meaning assignment in (36). Rather, it seems that the unified function of tonal specification in Hausa is to indicate a choice from a binary set of alternative interpretations, where the exact pairing of tone and meaning is conventionalized to some degree. In some cases, the choice may be supported by iconic or other paralinguistic features, such as, e.g., 
with proximal and distal demonstratives, or with the rising tone of questions (Gussenhoven 2004). In view of these facts, I propose the revised meaning of the lexically underspecified skeleton daa in (38). (38) differs from (26) in that the two constraining index sets are not flattened by set union, but kept apart as two alternative presuppositional index sets. From these two alternatives, HL tone selects for the first and L tone for the second.

$$
\begin{aligned}
& \llbracket \mathrm{daa} \rrbracket=\lambda \mathrm{p}_{<\mathrm{i}>} . \lambda \mathrm{i}: \mathrm{i} \in \mathrm{TOP}_{\mathrm{i}} \wedge \mathrm{i} \in \mathrm{ALT} \\
& A L T \in\left\{\left\{\underline{\left.i^{\prime} \mid \mathrm{i}^{\prime}<\mathrm{ic}_{\mathrm{c}}\right\}},\left\{\mathrm{i}^{\prime} \mid \mathrm{t}(\mathrm{ic}) \leq \mathrm{t}\left(\mathrm{i}^{\prime}\right), \neg\left(\mathrm{ic}_{\mathrm{C}} \leq \mathrm{i}^{\prime}\right)\right\}\right\} \cdot \mathrm{p}(\mathrm{i})\right.
\end{aligned}
$$

To conclude, whereas the flattened meaning specification in (26) may be sufficient to account for fake tense phenomena in English with fully identical surface realizations, (38) seems better suited for capturing the individual meaning contributions of underspecified daa and its surface realizations dâa and dàa in Hausa. Moreover, given that sets of indexes are propositions, the more richly articulated semantic structure in (38) provides another empirical argument for analyzing clausal conjunctions or disjunctions as denoting sets of distinct propositions (Kratzer 1977, 2012).

\subsection{Further predictions}

The analysis of fake past in Hausa makes several additional predictions. First, it correctly accounts for the disambiguating effect of optional temporal dâa in indicative metaphysical conditionals to yield a hypothetical past reading in (21). The meaning of the antecedent clause is shown in (39), where the temporal reference of the antecedent is backshifted relative to $\mathrm{i}_{\mathrm{c}}$ (=now). The non-ambiguity follows from the fact that temporal dâa cannot shift the evaluation to $\mathrm{CF}$-indices.

$$
p=\lambda i: i \in T O P I, i \in\left\{\underline{\left.i^{\prime} \mid i^{\prime}<i_{C}\right\}} . \exists i^{\prime} \text { children come back at } i^{\prime} \text { and } t\left(i^{\prime}\right) \subset t(i)\right.
$$

Secondly, dàa and dâa are modifiers of type $<$ it,it $>$ and do not change the type of their propositional complement. Hence, they should be able to co-occur in past counterfactuals. This prediction is also borne out, as shown in the elicited (40):

(40) In dàa dâa Binta taa sha maagàni nnàn d'àazu, dàa dâa taa yi sauk'i if CF PST Binta 3F.PFV drink medicine DEF then CF PST 3SG.F.PFV do.relief 'If Binta had taken the medicine back then, she would have been better.'

A precondition for such double occurrences is that $i_{c}$ is backshifted from the actual here-now to a local context index by fitting dàa/dâa with an additional ic-argument slot. This is comparable to the temporal backshift of tтоP from utterance time to a local context time under embedding; see Ogihara 1995. With temporally backwardshifted CFs, such as (40), the counterfactual indices are determined relative to a local index $i_{c}$, which is temporally backshifted against the utterance time index $i_{c}$ ". 


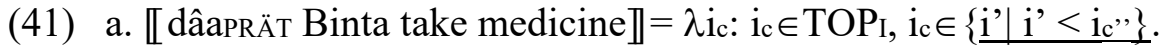
$\exists i$ ' $\left[\right.$ Binta takes medicine at $\mathrm{i}^{\prime}$ ' and $\left.\mathrm{t}\left(\mathrm{i}^{\prime}{ }^{\prime}\right) \subset \mathrm{t}\left(\mathrm{i}_{\mathrm{c}}\right)\right]$

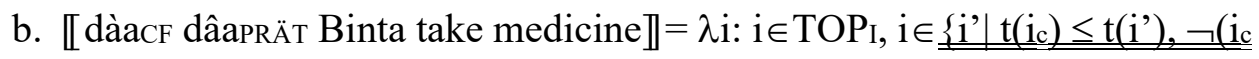
$\left.\left.\leqq \mathrm{i}^{\prime}\right)\right\} \& \mathrm{i}_{\mathrm{c}} \in\left\{\mathrm{i}^{\prime} \mid \mathrm{i}^{\prime}<\mathrm{i}^{\prime}{ }^{\prime}\right\} . \exists \mathrm{i}^{\prime}$ '[Binta takes medicine at $\mathrm{i}^{\prime \prime}$ and $\left.\mathrm{t}\left(\mathrm{i}^{\prime \prime}\right) \subset \mathrm{t}\left(\mathrm{i}_{\mathrm{c}}\right)\right]$

If correct, there may actually be two ways of accessing CF indices in the past in Hausa: through a combination of $\mathrm{CF}$ evaluated against the utterance time plus perfect aspect (with tun(i)), or through the combination of past dâa and CF dàa!

Finally, as the meaning contribution of dâa (and dàa) is presuppositional, it is invisible to negation (42) (elicited), and it cannot be made at-issue under focus. The contrasting elements dâa and yànzu in (43) from Newman (2000: 35) are not foci, but topics. And dâa is illicit as an at-issue fragment answer to a when-question, (44), in contrast to the at-issue adverbial jiyà 'yesterday'. The facts suggest that dâa and dàa are presuppositional frame-setters for the topical evaluation index:

$\begin{array}{lllllll}\text { * Baa dâa } & \text { bá (nee) } & \text { na } & \text { san } & \text { haká zâa yi } \\ \text { NEG } & \text { PST } & \text { NEG FOC } & \text { 1SG.PFV know } & \text { so } & \text { FUT-3SG happen }\end{array}$

INTENDED: 'I didn't know before that this would happen (but only now).

dâa i-nàa ciyar dà ìyaalìi, àmmaa yànzu dai, ìnâ!
PST 1SG-IPFV feeding $P$ family but now

'Formerly, I could provide for my family, but nowadays, no way!'

$$
\begin{array}{lll}
\text { Q: Yaushe Musa ya } & \text { dawo? A: Jiyà / *Dâa. } \\
\text { when M. 3SG.M.PFV return } & \text { yesterday PST } \\
\text { 'When did Musa return?' } & & \text { 'Yesterday.'/ \# 'Long ago.' }
\end{array}
$$

\section{Conclusion}

The paper presents a novel paradigm of fake past $=$ EXCL in the grammatically tenseless language Hausa (Chadic): Unlike in Greek or English, past and counterfactual readings in Hausa are not expressed by possibly semantically inert inflectional morphology on $\mathrm{V}$, but by a topical operator element daa in the left periphery. The formal analysis of daa as a general exclusion operator (Iatridou 2000) is cast in the modified branching-world model of von Prince (2019): The skeletal core daa comes with a lexically underspecified meaning that corresponds to the meaning of English Simple Past morphology in von Prince (2019), modulo a slight modification. The meaning of daa restricts evaluation to actual past or counterfactual indices. Tonal specification then results in the surface forms dâa (past) and dàa $(\mathrm{CF})$, which function as not-at-issue frame-setters on the evaluation index $i$. Finally, other tenseless languages may also employ temporal-aspectual markers for expressing CF, such as, e.g., the temporal adverb $k a$ 'ch 'formerly' in tenseless Yucatan Maya (Bohnemeyer 2018). 
Fake Tense in Hausa Counterfactuals

\section{References}

Abusch, Dorit. 1985. On verbs and time. Amherst, Mass.: UMASS PhD dissertation.

Arregui, Ana C. 2007. When aspect matters: The case of would-conditionals. Natural Language Semantics 15(3): 221-264. https://doi.org/10.1007/s11050007-9019-6

Arregui, Ana C. 2009. On similarity in counterfactuals. Linguistics and Philosophy, 23(3), 245-278. https://doi.org/10.1007/s10988-009-9060-7

Bohnemeyer, Juergen. 2018. Counterfactuals in Yucatec. Baby steps beyind the tense-mood counfound. Semantics Colloquium, University of British Columbia, September 28, 2018.

Biezma, Maria. 2011. Optatives: deriving desirability from scalar alternatives. In Ingo Reich et al. (eds.), Sinn und Bedeutung (SuB), vol.15, 117-132. Konstanz: Universität Konstanz Open Journal Systems.

Dudman, Victor H. 1983. Tense and time in English verb clusters of the primary pattern. Australian Journal of Linguistics 3(1): 25-44.

Dudman, Victor H. 1984. Conditional interpretations of if-sentences. Australian Journal of Linguistics 4(2):143-204.

von Fintel, Kai \& Sabine Iatridou. 2003. How to say ought in Foreign: The composition of weak necessity modals. In Jacqueline Gueron \& Jacqueline Lecarme (eds.), Time and Modality, 115-141. Dordrecht: Springer.

Grønn, Atle\& Arnim von Stechow. 2009. Temporal interpretation and organization of subjunctive conditionals. Ms. University of Oslo.

Grosz, Patrick G. 2013. Optativsatz. In Hans Altmann et al. (eds.), Satztypen des Deutschen, 146-170. Berlin: de Gruyter.

Gussenhoven, Carlos. 2004. The Phonology of Tone and Intonation. Cambridge: Cambridge University Press.

Hartmann, Katharina \& Malte Zimmermann. 2007. Exhaustivity marking in Hausa: A reevaluation of the particle nee/cee. In Enoch O. Aboh et al. (eds.), Focus Strategies in African Languages: On the Interaction of Focus and Grammar in Niger-Congo and Afro-Asiatic, 241-263. Berlin: de Gruyter.

Iatridou, Sabine. 2000. The grammatical ingredients of counterfactuality. Linguistic Inquiry 31(2): 231-270.

Ippolito, Michaela. 2003. Presuppositions and implicatures in counterfactuals. Natural Language Semantics 11(2): 145-186.

Ippolito, Michaela. 2013. Subjunctive Conditionals: A Linguistic Analysis. Cambridge, MA: MIT Press.

Karawani, Hadil. 2014. The real, the fake and the fake fake in counterfactual conditionals, crosslinguistically. Amsterdam: Universiteit van Amsterdam PhD dissertation. 
Karawani, Hadil \& Hedde Zeijlstra. 2013. The semantic contribution of the past morpheme in Palestinian counterfactuals. Journal of Portuguese Linguistics 12(1): 105-119.

Kaufmann, Stefan. 2005. Conditional truth and future reference. Journal of Semantics 22(3): 231-280.

Klein, Wolfgang. 1994. Time in Language. New York: Routledge.

Kratzer, Angelika. 1977. What 'must' and 'can' must and can mean. Linguistics and Philosophy 1: 33-355.

Kratzer, Angelika. 1998. More Structural Analogies Between Pronouns and Tenses. In Devon Strolovitch \& Aaron Lawson (eds.), Semantics and Linguistic Theory (SALT), vol.8, 92-110. Ithaca, NY: Cornell University.

Kratzer, Angelika. 2012. Modals and Conditionals: New and Revised Perspectives. Oxford: Oxford University Press.

Leben, William R., Sharon Inkelas \& Mark Cobler. 1989. Phrases and Phrase Tones in Hausa. In Paul Newman und Robert D. Botne (eds.), Current Approaches to African Linguistics, vol.5, 45-61. Dordrecht: Foris.

Lewis, David. 1986. On the Plurality of Worlds. Oxford: Blackwell.

Mucha, Anne. 2013. Temporal interpretation in Hausa. Linguistics and Philosophy 36(5): 371-415. https://doi.org/10.1007/s10988-013-9140-6

Mucha, Anne. 2015. Temporal interpretation and cross-linguistic variation A formal semantic analysis of temporal and aspectual reference in Hausa and Medumba. Potsdam: Universität Potsdam PhD dissertation.

Newman, Paul 2000. The Hausa Language. An Encyclopedic Reference Grammar. New Haven, London: Yale University Press.

Newman, Paul \& Roxana Ma Newman. 1981. The question morpheme q in Hausa. Afrika und Übersee 64: 35-46.

Ogihara, Toshiyuki. 1995. The semantics of tense in embedded clauses. Linguistic Inquiry 26(4): 663-679.

Ogihara, Toshiyuki. 2000. Counterfactuals, temporal adverbs, and association with focus. In Brendan Jackson \& Tanya Matthews (eds.), Semantics and Linguistic Theory (SALT), vol.10, 115-131. Ithaca, NY: Cornell University.

Prior, Arthur N. 1957. Time and modality. Oxford: Oxford University Press.

Prior, Arthur N. 1967. Past, present and future. Oxford: Oxford University Press

von Prince, Kilu. 2017. Paradigm-induced implicatures of TAM markers: The case of the Daakaka distal. In Robert Truswell et al. (eds.), Sinn und Bedeutung (SuB), vol.21(2), 969-984. Konstanz: Universität Konstanz Open Journal Systems.

von Prince, Kilu. 2019. Counterfactuality and past. Linguistics and Philosophy 42(6): 577-61. https://doi.org/10.1007/s10988-019-09259-6

Romero, Maribel. 2014. 'Fake Tense' in counterfactuals: A temporal remoteness approach. In Luka Crnic \& Uli Sauerland (eds.), The Art and Craft of 
Fake Tense in Hausa Counterfactuals

Semantics: A Festschrift for Irene Heim, vol.2, 47-63. Cambridge, MA: MIT Working Papers in Linguistics.

Schulz, K. (2014). Fake tense in conditional sentences: A modal approach. Natural Language Semantics, 22(2), 117-144. https://doi.org/10.1007/s11050-0139102-0

Smith, Carlota S. \& Mary S. Erbaugh. 2005. Temporal interpretation in Mandarin Chinese. Linguistics 43(4): 713-756. https://doi.org/10.1515/ling.200543.4. 713

von Stechow, Arnim. 2009. Tenses in compositional semantics. In Wolfgang Klein (ed.), The Expression of Time in Language, 129-166. Berlin: de Gruyter.

Thomason, Richmond H. 1970. Indeterminist time and truth-value gaps. Theoria 36(3): 264-281.

Thomason, Richmond H. 1984. Combinations of tense and modality. In Dov M. Gabbay \& Franz Guenthner (Eds.), Handbook of Philosophical Logic, vol.2, 135-165. Dordrecht: Reidel.

Yalcin, Seth. 2016. Modalities of Normality. In Nate Charlow and Matthew Chrisman (eds.), Deontic Modality, 230-55. Oxford: Oxford University Press.

\author{
Author \\ Malte Zimmermann \\ Universität Potsdam \\ Dept. of Linguistics \\ Karl-Liebknecht-Straße 24-25 \\ D-14476 Potsdam, Germany \\ mazimmer@uni-potsdam.de
}

